\title{
Quantifying the Use of Dynamics in Western Keyboard Music: Lessons and Problems
}

\author{
DOROTTYA FABIAN \\ Empirical Musicology Group, University of New South Wales
}

\begin{abstract}
Ladinig and Huron's (2010) investigation of the relationship between mode (major-minor) and dynamics in Classical and Romantic piano music indicated higher levels of dynamics for compositions from the Classical period but only in major-mode pieces. This was contrary to the expectation that minor mode pieces from the Romantic era would be louder because romantic composers may have intended to convey seriousness, passion or even aggression, rather than sadness. Although the methodology was carefully crafted to enable necessary control for a quantitative study, it also contributed to the questionable relevance of the results. It is arguable whether the chosen repertoire is typical, whether initial markings in the score have a true bearing on the dynamic characteristics of a piece and whether notated dynamics are reliable data due to historical notation conventions and later editorial practices.
\end{abstract}

Submitted 2010 July 20; accepted 2010 July 25.

KEYWORDS: dynamics, minor mode, editing, music historiography, Romantic music

IN a series of intriguing papers by Huron and his collaborators published recently in this journal, fundamental assumptions about the relationship between mode (major or minor) and other inscribable parameters of Western classical music have been tested-inscribable in the sense that the composer can communicate his/her intention by way of notating a directive that sets the boundaries of that parameter for the performer. In the first instance (Post \& Huron, 2009) the relationship between tempo and mode was investigated; in the paper under consideration here, dynamics and mode (Ladinig \& Huron, 2010). In both cases the practices of different historical periods were compared yielding somewhat unexpected results. In case of tempo, no general trend was found but Baroque and Classical period pieces in minor keys tended to have slow tempo indications more frequently than those from the early Romantic period. Based on the discussion of this result, namely that minor mode music in the Romantic period might not be primarily associated with sadness but rather with passion, seriousness and even aggression, Ladinig and Huron hypothesized that minor-mode pieces from the Romantic period are likely to have louder dynamics than their counterparts from the Classical period. Again the results turned out to be somewhat surprising: an overall trend towards quieter notated dynamics over time and only in major-mode pieces.

As a researcher trained by historical musicologists rather than data-driven empiricists I find such studies that stop me in my tracks and make me re-think received wisdom refreshing; especially, since the methodology is carefully designed and the discussion considers possible historical or stylistic explanations reasonably thoroughly. Upon reflection, however, I wonder about the knowledge gained for three reasons.

Firstly, to create sufficient control and eliminate potential bias, the data collection is limited to pieces that might not be representative of the repertoire from a canonical point of view. If the study is supposed to test broad claims of music historians or extra-musical associations of "Western-enculturated listeners" then the data should be roughly the same works on which music historians build their narrative and listeners rely as reference. Ladinig and Huron examined collections of preludes by Clementi, Hummel, Heller, Herz, Scryabin and Blumenfield. Apart from the fact that half of these composers are little known, there is also the issue of classifying Clementi and Hummel as composers of the Classical period. Surely their dates would justify this, but the style of their compositions that I am familiar with shows strong elements of musical romanticism and tends to be discussed in relation to Beethoven and the developing piano technique heralding nineteenth-century sensibilities. But the specific detail is not really the issue to argue here; what is important is the question whether any of the listed composers or their collections of preludes are typical for the designated periods. Unfortunately music historians generally fail to provide an 
answer even though several of them have argued for a re-evaluation of the established canon. Although recent music history books tend to emphasize the social-cultural-economic context that fosters a more inclusive account of musical practitioners, activities and their relationship to style, the characteristics of each style are established and exemplified primarily by the output of the "great and famous" either at the time or since.[1] A lesser known composer might be composing all too typical works (like most "run-ofthe-mill" professionals) but they may not conform to every aspect of a given compositional trend as established by historical musicologists or assumed by the listening public who never encounters their pieces. Using their output to gain "objective" information about tendencies or regularities in Western music is therefore of questionable value.

Secondly, limiting investigations of the relationship between mode and dynamics to the beginning of pieces does not seem to have much ecological/practical validity. The authors acknowledge that compositions tend to include modulations from major to minor mode or vice versa and this could "cause confusion when coding the relationship between mode and dynamics" (p. 3). However, the same applies to dynamics as well. It is quite conceivable that a passionate and serious piece would start soft (brewingforeboding-mysterious) but overall would be loud (see Liszt's B minor Sonata, for instance) and the listener would remember it as loud. The delimitation of the data assists quantification but ignores the nature of the music that it ostensibly wants to investigate.

My final reservation is also related to data collection, namely the problem of consulting scores. The conventions of music notation have changed considerably over time. During the Baroque and the better part of the Classical periods, dynamics were rarely indicated, especially at the beginning of a piece. To be precise, usually only soft dynamics were indicated because the assumption was that the music would start with "normal/lively", that is forte, dynamics. By the same token, if a composer wanted more than "normal" he marked the score $f f$. Furthermore, composers prior to Beethoven rarely used the full scale of dynamics typically found in later scores; $m p$ and $m f$ markings are extremely rare in original classical period sources while quite common in later repertoire. The more nuanced markings of later scores may have contributed to the apparent softening of dynamics. In addition, since soft dynamics tended to be marked pre-1800 as well as thereafter, dynamics should actually show an increase in minor mode pieces if "Romantic music is more likely than Classical music to employ the minor mode to represent or convey affects that are associated with higher dynamic levels" (Ladinig \& Huron, 2010, p. 1).

A related issue is the reliability of editions. As music publishing started to flourish around the end of the $18^{\text {th }}$ century and as the distinction between performer and composer became more pronounced, composers began to notate more and more of what used to be the prerogative of the performer or what could be easily established with the composer being present at the performance, the usual practice even with Mozart. Nevertheless as those involved in critical editions and the study of autograph and other manuscript scores and first editions know all too well, there were composers who were more pedantic and detailed in their markings while others left the music bereft of performance indicators. The problem for a study like Ladinig and Huron's is that only major composers have their works available in critical editions. Other repertoires may contain undocumented editorial input impacting on dynamic markings. Again one could argue that this would likely bias the data in favour of the hypothesis, but my reservations underline the fact that, to me, the final sentence of the paper should read: Further research is necessary (not just warranted).

\section{NOTES}

[1] By far the best and most comprehensive revisionist music history recently published is Richard Taruskin's magisterial 5 volume The Oxford History of Western Music (2005, Rev. 2010). Neither Henri Herz nor Felix Blumenfeld is listed in the Index to volume 3: Music in the Nineteenth Century; but both Clementi and Hummel are (and both are absent from volume 2 that deals with the Classical period). Of Heller, Taruskin has the following to say: "More direct echo or emulation of Chopin's uncomplicated fragment can be found in composers of the next generation. Stephen Heller (1813-88), a Hungarian-born pianist composer who made his home, like Chopin, in Paris, was only three years Chopin's junior, but he had barely achieved notice by the time of the Polish composer's death [1849], and then only as a composer of technical studies. His more important works mainly belong to the later decades. First among them was a set of character pieces with the emblematically romantic title Spaziergänge einer Einsamen ("Solitary rambles"), published in 1851. The last item, a harried vivace, ends the cycle with an unresolved diminished-seventh chord, the equivalent of ending a letter or a story or-most typically—a lyric poem 
with an ellipsis (“...”). Except for the startling effect at the end (startling, that is, in retrospect, when one realizes that it was the end), the piece is fairly innocuous, and so were the many popular stories and poems that abused the device of ellipsis, turning it eventually into a cliché (Ex. 7-9)." (Taruskin, 2010: 361). Taruskin also discusses the prelude genre (p. 351) and describes Clementi and Hummel's collections as "didactic models" for "modulatory transitions between recital items for pianists who were incapable of improvising their own." He then contrasts these to Chopin's "vividly if enigmatically expressive performance pieces, albeit in an 'improvisatory' style."

\section{REFERENCES}

Ladinig, O., \& Huron, D. (2010). Dynamic levels in Classical and Romantic keyboard music: Effect of musical mode. Empirical Musicology Review, Vol. 5, No. 2, pp. 51-56.

Post, O., \& Huron, D. (2009). Music in minor modes is slower (except in the Romantic period). Empirical Musicology review, Vol. 4, No. 1, pp. 1-9.

Taruskin, R. (2010). The Oxford History of Western Music. New York: Oxford University Press. 